\title{
Cotton induced bronchoconstriction detected by a forced random noise oscillator
}

\author{
M-J SEPULVEDA, ' J L HANKINSON,' $R$ M CASTELLAN,' AND J B COCKE²
}

From the Division of Respiratory Disease Studies, ' National Institute for Occupational Safety and Health (NIOSH), Morgantown, West Virginia, and US Department of Agriculture, ${ }^{2}$ Cotton Quality Research Station, Clemson, South Carolina, USA

ABSTRACT Lung function responses to inhaled cotton dust were evaluated in a group of 58 healthy subjects by spirometry (MEFV curves) and forced random noise impedance parameters. Twenty-one of these subjects were also examined by body plethysmography to assess changes in airway resistance (Raw). For the study group as a whole, alterations in lung mechanical function after exposure to cotton dust were detected by maximal expiratory volumes and flows ( $\mathrm{p}<$ $0.001)$ and impedance parameters $(p<0.01)$ but not by Raw. Subjects showing responses in MEFV curves also showed increases in Thevenin or effective resistance at low frequencies $\left(R_{1}\right.$, $\mathbf{R}_{5-9}, \mathbf{R}_{5-9}\left(\mathbf{R}_{20-24}\right)$, suggesting that the limitation of flow occurred predominantly in the peripheral airways. By contrast, non-responders on MEFV measurements were found to have significant increases in effective resistance both at low and at high frequencies $\left(R_{1}, R_{5-9}, R_{20-24}\right)$, suggesting a central airways effect. MEFV curve non-responders also exhibited a significantly lower baseline effective resistance profile than MEFV curve responders. The data indicate that under the conditions of the experiment measures of the Thevenin resistance (real part of impedence) by the forced random noise method are reliable indicators of cotton induced bronchoconstriction. Measurement variability, however, suggests that, at present, these are more appropriate for group studies and should remain adjuncts to standard tests of lung function such as spirometry.

Early attempts to examine total respiratory impedance were based on the application of forced sinusoidal pressure oscillations at the mouth over a limited range of frequencies.' A more recent method has used forced random noise oscillations which cause less discomfort and permit observations of impedance over an expanded frequency range. ${ }^{2}$ This technique has been used to examine respiratory impedance parameters including total respiratory resistance (Thevenin or effective resistance) and its central and peripheral components. ${ }^{3-5}$ Studies in man have suggested that random noise parameters of respiratory impedance are reliable and sensitive measures of mechanical alterations resulting from pulmonary disease and induced bronchoconstriction. ${ }^{267}$

The purpose of the present study was to examine acute lung function responses to inhaled cotton dust in healthy subjects by the forced random noise tech-

Received 25 April 1983

Accepted 27 October 1983 nique of Pimmel et al..$^{7}$ To assess the ability of these measurements to detect changes in pulmonary function, spirometry and plethysmography were also carried out.

\section{Methods}

\section{STUDY POPULATION}

Criteria used in the selection of study subjects have been described in detail elsewhere. ${ }^{8}$ In brief, informed consent was obtained from healthy adult volunteers from the Clemson, South Carolina, area. Participation did not require a current or previous history of exposure to cotton dust. Subjects were exposed for six hour periods on separate occasions to no dust and a controlled concentration of cotton dust ( $1 \mathrm{mg} / \mathrm{M}^{3}$ by vertical elutriator) if they had a baseline $\mathrm{FEV}_{1}$ of at least $80 \%$ of predicted. Sixty one subjects who showed at least a $5 \%$ mean decrement in FEV during two exposures to cotton relative to their $\mathrm{FEV}_{1}$ changes during two clean room exposures were selected for further study. The 
current investigation includes 58 of these 61 individuals, three having withdrawn.

\section{STUDY PROTOCOL}

The subjects received one exposure to no dust and one exposure to cotton dust separated by an interval of 72 hours. Their acute lung function response was determined by spirometry and by a forced random noise oscillator. In addition, a subgroup of 21 subjects, preselected for their ability to perform adequate panting manoeuvres, underwent assessment of airway resistance (Raw) in a body plethysmograph. On test days, the subjects were examined sequentially by random noise oscillator, plethysmograph, and spirometry just before entering the exposure chamber and immediately after a six hour exposure. Smoking was not permitted during the exposure periods, and subjects were allowed to leave the room only for brief restroom breaks. All the tests on each individual were completed in less than 10 minutes and were performed by the same technicians who were not informed about the nature of the exposure.

\section{EXPOSURE}

Exposures took place in a room ventilated with exhaust air from a cardroom. For cotton dust exposures, the same blended, strict low middling cotton was carded at a constant production rate. Respirable dust concentration was measured using four vertical elutriators, one in each quadrant of the exposure room. The mean dust concentration in the room was determined gravimetrically approximately once an hour, and the desired concentration was maintained by varying the amount of dust laden air entering the chamber. The desired concentration of cotton dust was 0.45 to $0.48 \mathrm{mg} / \mathrm{M}^{3}$. Based on our experience with cotton dust, this concentration of the particular cotton used was considered safe for participants and sufficient to produce a mean group $\mathrm{FEV}_{1}$ decrement of approximately $3 \%$.

\section{TESTS OF LUNG FUNCTION}

Spirometry was performed with a rolling seal spirometer (Model 840, Ohio Med Products) directly interfaced with a computer (LSI 11/23, Digital Equipment Corp) and oscilloscope. At least five forced expiratory manoeuvres from maximum inspiration were obtained during each test. From a minimum of three manoeuvres conforming to American Thoracic Society criteria," the largest $\mathrm{FEV}_{1}$ and FVC were selected regardless of the curve(s) on which they occurred. Flow rates were obtained by aligning each subject's flow volume curves at TLC and using the largest observed flows from the resulting maximum envelope. Where used, predicted values for $\mathrm{FEV}_{1}$ and $\mathrm{FVC}$ are those of Knudson and co-workers, ${ }^{10}$ corrected by a factor of 0.85 for blacks.

Measurements of airway resistance (Raw) were made with a pressure-volume or flow plethysmograph (8000 AutoBox, SRL Medical Inc). Raw was obtained from the average of four panting cycles ( $2 \mathrm{~Hz}$ ) using data in the flow range of $\pm 0.5 \mathrm{l} / \mathrm{s}$. Least squares fit lines were applied to flow pressure curves in this range and Raw was calculated by subtracting mouth flow meter and shutter resistance from the inverse slope. Mouth and box flowmeters were calibrated four times a day using a standardised flow signal from a motor driven piston of $7 \cdot 10$ litre displacement. The mouth pressure transducer was calibrated daily with a water manometer.

Respiratory impedance was measured with a forced random noise system similar to that described by Pimmel and associates.' A random pressure (bandwidth 2 to $45 \mathrm{~Hz}$ ) was introduced into a subject's respiratory system through the mouthpiece by means of a loudspeaker mounted in an enclosure. The loudspeaker was driven by a random noise source and the corresponding pressure and flow at the mouth were measured over 32 seconds of quiet tidal breathing. Each subject started the manoeuvre at functional residual capacity, wearing nose clips and supporting his cheeks. The pressure and flow signals were digitalised by a computer (LSI 11/23, Digital Equipment Corp) with a sampling rate of 200 samples per second, and total respiratory impedance was calculated using the spectral analysis technique described by Michaelson et al. ${ }^{2}$ The mechanical impedance of the oscillator system was calculated before testing of subjects, and was used to correct total impedance measured by the system to yield only respiratory impedance. To prevent an accumulation of carbon dioxide in the enclosure, a bias flow of fresh air was also supplied to the enclosure via a low impedance tube, tuned to prevent loss of the random noise forcing signal.

For the purposes of the present study, only the real part of the total respiratory impedance (Thevenin or effective resistance $R_{T H}$ ) was used. From the relationship of total resistance versus frequency, four parameters were calculated.' The resistance was averaged over the frequency range from 5 to $9 \mathrm{~Hz}\left(\mathrm{R}_{5-9}\right)$ and from 20 to $24 \mathrm{~Hz}\left(\mathrm{R}_{20-24}\right)$, providing measures of the resistance at low and high frequencies. The $R_{5-9} / R_{20-24}$ ratio was also determined as a measure of the frequency dependence of resistance. A linear fit to the $\log$ of $R_{T H}$ versus the $\log$ of frequency was made and the resistance at $1 \mathrm{~Hz}\left(R_{1}\right)$ was determined by extrapolating resistance to the one $\mathrm{Hz}$ value.

To calibrate and validate the impedance measur- 
ing system, simulation resistors were constructed of many separate pieces of small glass tubing mounted in parallel inside a plastic tube. The mechanical impedance of these calibrating resistors was determined by forcing several different constant flows through the resistors and measuring the corresponding pressures. In addition, the resistances were determined as a function of frequency by generating sinusoidal pressure signals and measuring the corresponding flows. One of these calibrating resistors was later used to check the impedance measuring system in the field before each testing session. Only $\mathbf{R}_{\mathrm{TH}}$ data where the corresponding coherence was greater than 0.85 were used in our analysis. This almost always required the elimination of $R_{T H}$ values at frequencies less than $5 \mathrm{~Hz}$. At frequencies greater than $5 \mathrm{~Hz}$, however, the coherence was typically greater than $0 \cdot 95$.

\section{STATISTICAL ANALYSIS}

Comparisons of mean values were performed using either a Student's $t$ test or a "paired" $t$ test available through Statistical Analysis System (SAS). For the discriminant analysis, a Bayes bisector classifier ${ }^{11}$ was developed to separate $\mathrm{FEV}_{1}$ shift changes on the control day from $\mathrm{FEV}_{1}$ shift changes on the day of cotton dust exposure.

\section{Results}

Demographic characteristics and baseline spirometry of the study group are shown in table 1 . The subjects were relatively young and had accumulated few years of cotton mill work and pack-years of smoking. The ability to perform acceptable panting manoeuvres in the body plethysmograph appears to have been randomly distributed in the study population. On dust days an elutriated cotton dust concen-
Table 1 Characteristics of participants

\begin{tabular}{|c|c|c|c|}
\hline & \multicolumn{2}{|c|}{ Plethysmography } & \multirow[t]{2}{*}{ All } \\
\hline & Yes & No & \\
\hline $\begin{array}{l}\text { No } \\
\text { Mean age (y) (SE) }\end{array}$ & $\begin{array}{l}21 \\
31(2)\end{array}$ & $\begin{array}{l}37 \\
36(2)\end{array}$ & $\begin{array}{l}58 \\
34(1)\end{array}$ \\
\hline $\begin{array}{l}\text { Sex: } \\
\quad \% \text { Female }\end{array}$ & 52 & 60 & 57 \\
\hline $\begin{array}{l}\text { Race: } \\
\text { \% White } \\
\text { Smoking: }\end{array}$ & 86 & 86 & 86 \\
\hline $\begin{array}{l}\% \text { Current smokers } \\
\% \text { Never smokers } \\
\text { Mean pack-years (SE) }\end{array}$ & $\begin{array}{l}62 \\
29 \\
8(2)\end{array}$ & $\begin{array}{l}51 \\
41 \\
.6(2)\end{array}$ & $\begin{array}{l}55 \\
36 \\
7(1)\end{array}$ \\
\hline $\begin{array}{l}\text { Mean years cotton mill work } \\
\text { (SE) } \\
\text { Dust exposure, } \mathrm{mg} / \mathrm{M}^{3} \text { : }\end{array}$ & $2(1)$ & $2(1)$ & $2(1)$ \\
\hline $\begin{array}{l}\text { Control } \\
\text { Cotton }\end{array}$ & $\begin{array}{l}0.03 \\
0.46\end{array}$ & $\begin{array}{l}0.03 \\
0.46\end{array}$ & $\begin{array}{l}0.03 \\
0.46\end{array}$ \\
\hline $\begin{array}{l}\text { Baseline lung function: } \\
\% \text { pred FEV }(\mathrm{SE}) \\
\% \text { pred FVC }(\mathrm{SE})\end{array}$ & $\begin{array}{r}94(3) \\
102(4)\end{array}$ & $\begin{array}{r}94(2) \\
102(2)\end{array}$ & $\begin{array}{r}94(2) \\
102(2)\end{array}$ \\
\hline
\end{tabular}

tration of $0.46 \mathrm{mg} / \mathrm{M}^{3}$ was attained in the exposure chamber.

The population mean values $\pm \mathrm{SD}$ of baseline measurements of Raw, $R_{1}, R_{5-9}$, and $R_{20-24}$ were $1 \cdot 07 \pm 0 \cdot 32,3 \cdot 81 \pm 2 \cdot 82,3 \cdot 46 \pm 1 \cdot 07$, and $3 \cdot 29 \pm$ $0.76 \mathrm{~cm} \mathrm{H}_{2} \mathrm{O}$ per litre per second, respectively. These values for impedance derived parameters show that the Thevenin resistance $\left(R_{T H}\right)$ was not frequency dependent before exposure to cotton dust-that is, no significant differences existed between the various $R_{T H}$ values over the specified frequencies. Baseline measurements of $R_{T H}$ did not differ in sex, smoking, and plethysmograph subgroups.

Table 2 shows the mean percentage changes in the spirometric indices over a six hour exposure to cotton dust relative to the same changes during the control exposure. All spirometric parameters exhibited significant declines in response to cotton dust exposure $(p<0.001)$. Decrements for $\mathrm{FEF}_{75}$,

Table 2 Lung function response to control and cotton dust exposures

\begin{tabular}{|c|c|c|c|c|}
\hline & Control (1) & Cotton (2) & (2) Minus (1) & p-Value $(2-1)^{*}$ \\
\hline $\begin{array}{l}\text { Spirometry }(n=58) \\
\% \triangle \text { FEV }(\text { (SE) } \\
\% \triangle \text { FVC (SE) } \\
\% \triangle \text { PFR (SE) } \\
\% \triangle \text { FEF }_{s 0} \text { (SE) } \\
\% \triangle \text { FEF }_{75} \text { (SE) }\end{array}$ & $\begin{array}{l}0.8(0.5) \\
0.4(0.4) \\
1.7(0.5) \\
1.3(1.3) \\
7.0(3.0)\end{array}$ & $\begin{array}{l}-2.8(0.7) \\
=\quad 2.3(0.5) \\
=\quad 0.9(0.7) \\
=\quad 8.0(2.2) \\
-14.3(3.2)\end{array}$ & $\begin{array}{l}-3.6(0.7) \\
=\quad 2.7(0.5) \\
=2.6(0.7) \\
=\quad 9.3(2.0) \\
-21.3(3.6)\end{array}$ & $\begin{array}{l}0.0001 \\
0.0001 \\
0.0002 \\
0.0001 \\
0.0001\end{array}$ \\
\hline $\begin{array}{l}\text { Oscillator }(n=58) \\
\% \triangle \mathbf{R}_{1}(\mathrm{SE}) \\
\% \triangle \mathbf{R}_{5-9} \text { (SE) } \\
\% \triangle \mathbf{R}_{20-3}(\mathrm{SE}) \\
\% \triangle \mathbf{R}_{5-9} \mathbf{R}_{20-24}(\mathrm{SE})\end{array}$ & $\begin{array}{l}-5.6(3.9) \\
-2.9(2.2) \\
=0.9(2.6) \\
-1.2(1.5)\end{array}$ & $\begin{array}{r}20 \cdot 3(6 \cdot 1) \\
9 \cdot 7(2 \cdot 5) \\
6 \cdot 3(2 \cdot 6) \\
4 \cdot 0(1 \cdot 4)\end{array}$ & $\begin{array}{r}25 \cdot 9(7 \cdot 1) \\
12 \cdot 6(3 \cdot 5) \\
7 \cdot 2(4 \cdot 0) \\
5 \cdot 2(2 \cdot 1)\end{array}$ & $\begin{array}{l}0.0006 \\
0.0008 \\
0.0822 \\
0.0148\end{array}$ \\
\hline $\begin{array}{l}\text { Plethysmograph }(n=21) \\
\% \triangle \text { Raw (SE) }\end{array}$ & $5 \cdot 1(6 \cdot 0)$ & $9 \cdot 3(5 \cdot 8)$ & $4 \cdot 2(8 \cdot 9)$ & 0.6467 \\
\hline
\end{tabular}

$\% \Delta=(($ Postshift-preshift $) /$ preshift $) \times 100$.

${ }^{*}$ Paired $t$-test; $\mathbf{H}_{\mathbf{0}}$ : (cotton-control) $=0$. 


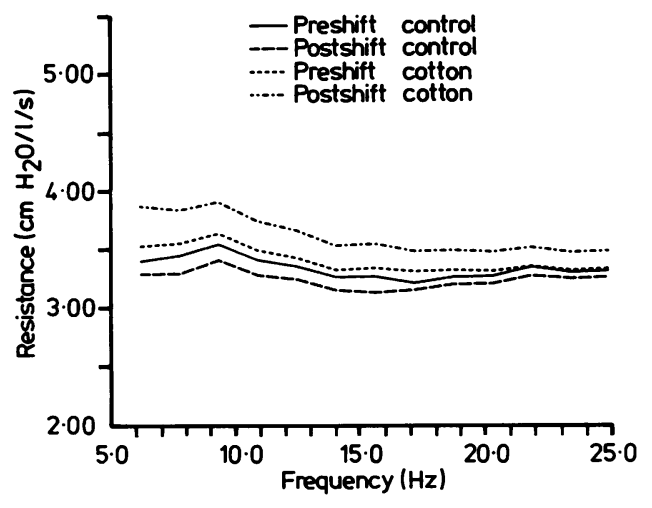

Fig 1 Average Thevenin resistance $\left(R_{T H}\right)$ as a function of frequency for the study group $(n=58)$ showing preshift and postshift data during control and cotton exposures.

$\mathrm{FEF}_{50}$, and $\mathrm{FEV}_{1}$ were greater than those for FVC and peak flow rate, and were similar in those with and those without Raw measurements (not shown).

A plot of the real part of the impedance of the respiratory system $\left(R_{T H}\right)$ is shown in fig 1 for the population both before and after dust and control exposures. In response to cotton dust, effective resistance $\left(R_{T H}\right)$ showed a larger increase at lower frequencies than at higher frequencies. Table 2 shows a comparison of these frequency specific resistance changes and Raw. Cotton exposure produced no significant changes in Raw and the average resistance between $20-24 \mathrm{~Hz}\left(\mathrm{R}_{20-24}\right)$. Nevertheless, measures of effective resistance at low frequencies $\left(\mathbf{R}_{1}, \mathbf{R}_{5-9}, \mathbf{R}_{5-9} / \mathbf{R}_{20-24}\right)$ were sensitive to cotton induced bronchoconstriction $(p<0.01)$.

To compare the detection of acute changes in lung function by forced random noise parameters with those obtained by spirometry, subjects were divided into two groups based on discriminant analysis of FEV $_{1}$ responses during cotton and control exposures. By discriminant analysis an $\mathrm{FEV}_{1}$ decrement of $1 \%$ best distinguished cotton and control responses. Two groups, one with $38 \mathrm{FEV}_{1}$ "responders" (group A) and the other with $20 \mathrm{FEV}_{1}$ "nonresponders" (group B) were identified. Both groups had similar exposure, baseline spirometry $\left(\mathrm{FEV}_{1}\right.$, FVC), age, sex, and smoking profiles. Demographic features and lung function responses for these groups are presented in table 3. For group A, as for the study group as a whole, all the spirometric indices examined and $R_{1}, R_{5-9}$, and the $R_{5-9} / R_{20-24}$ ratio showed significant dust related changes. For group $\mathrm{B}$, changes in pulmonary function were detected by the impedance derived measures $R_{1}$, $R_{5-9}$, and $R_{20-24}$ in the absence of spirometric changes.
Table 3 Demographic features and lung function changes by $F E V_{1}$ response status

\begin{tabular}{|c|c|c|}
\hline & Group $A$ & Group B \\
\hline \multirow{3}{*}{$\begin{array}{l}\text { Demography } \\
\text { No } \\
\text { Mean age (y) } \\
\text { \% Female } \\
\text { Smoking: } \\
\text { \% Current smokers } \\
\text { \% Non-smokers } \\
\text { Mean cotton mill years } \\
\text { Baseline lung function: } \\
\text { \% Predicted FEV } \\
\text { \% Predicted FVC }\end{array}$} & $\begin{array}{l}38 \\
34(2) \\
60\end{array}$ & $\begin{array}{l}20 \\
33(2) \\
50\end{array}$ \\
\hline & $\begin{array}{l}55 \\
39 \\
5 \quad 2 \cdot 1(0.5)\end{array}$ & $\begin{array}{l}55 \\
30 \\
2 \cdot 3(1 \cdot 5)\end{array}$ \\
\hline & $\begin{array}{r}95(2) \\
102(2)\end{array}$ & $\begin{array}{r}93(3) \\
101(3)\end{array}$ \\
\hline & Cotton minus control & Cotton minus control \\
\hline $\begin{array}{l}\% \triangle \text { FEV }_{1} \\
\% \triangle \text { FVC } \\
\% \triangle \text { PFR } \\
\% \triangle \text { FEF }_{50} \\
\% \triangle \text { FEF }_{75}\end{array}$ & $\begin{array}{l}-5 \cdot 6(0.9)^{*} \\
-4.0(0.7)^{*} \\
-4.0(0.8)^{*} \\
-14.4(2.6)^{*} \\
-30.6(4.0)^{*}\end{array}$ & $\begin{array}{r}0.2(0.8) \\
-0.2(0.7) \\
0.0(1 \cdot 0) \\
0.2(2.4) \\
-3.7(5 \cdot 3)\end{array}$ \\
\hline $\begin{array}{l}\text { Impedance parameters } \\
\% \triangle \mathbf{R}_{1} \\
\% \triangle \mathbf{R}_{5-9} \\
\% \triangle \mathbf{R}_{20-2} \\
\% \triangle \mathbf{R}_{5-9} \mathbf{R}_{20-24}\end{array}$ & $\begin{array}{l}22.5(7 \cdot 9) \dagger \\
9 \cdot 3(4 \cdot 0) \dagger \\
2 \cdot 9(5 \cdot 0) \\
6 \cdot 0(2 \cdot 7) \dagger\end{array}$ & $\begin{array}{l}32.6(14 \cdot 5) \dagger \\
18.9(6 \cdot 8) \dagger \\
15 \cdot 2(6 \cdot 6) \dagger \\
3.6(3 \cdot 1)\end{array}$ \\
\hline
\end{tabular}

$\% \Delta=(($ Postshift-preshift $) /$ preshift $) \times 100$.

SEs in parentheses.

$* p<0.001$.

$t_{\mathrm{p}}<0.03$.

Figure 2 shows the plots of the Thevenin resistance responses of groups A and B. Group A showed a statistically significant increase in $R_{T H}$ only at low frequencies, whereas group $B$ showed statistically significant $R_{T H}$ changes that were independent of frequency. Pre-exposure $R_{T H}$ also differed in the two groups. Group A (FEV 1 responders) had baseline $R_{1}, R_{5-9}$, and $R_{20-24}$ values that were significantly greater than those of group $B(p<$ 0.005).

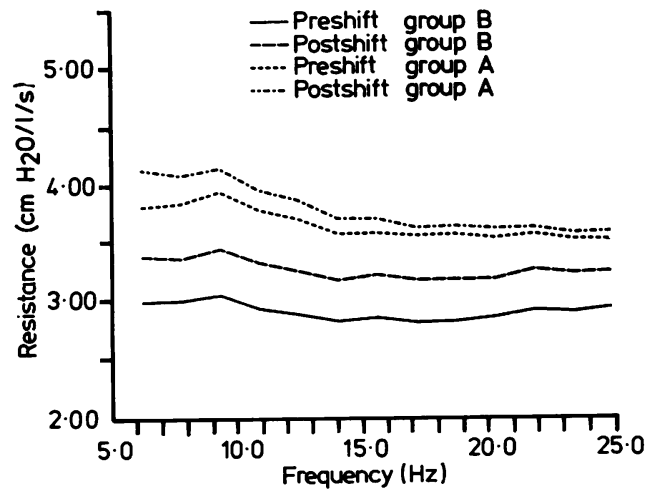

Fig 2 Average Thevenin resistance-frequency plots showing shift related responses to cotton dust in subjects with (group A) and without (group B) an FEV, decrement over same shift. 


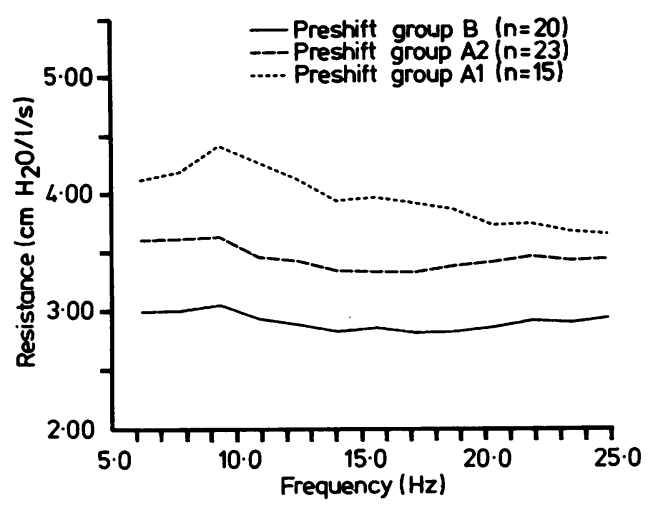

Fig 3 Average baseline Thevenin resistance profiles of subjects with greater than a $5 \% F E V_{1}$ decrement after exposure to cotton dust (group $A_{1}$ ), a 1-5\% decrement (group $A_{2}$ ), and less than a $1 \%$ decrement (group $B$ ).

To examine further the relation between lung function responses and pre-exposure $R_{T H}$ profiles, group A was divided into two groups, subjects with FEV $_{1}$ dust related decrements greater than $5 \%$ (group $A_{1}$ ) and subjects with $\mathrm{FEV}_{1}$ decrements of $1-5 \%$ (group $A_{2}$ ). The pre-exposure effective resistance in these groups is shown in fig 3 . The baseline effective resistance was highest in subjects with the largest $F E V_{1}$ response to cotton dust (group $A_{1}$ ), and lowest in those without an $\mathrm{FEV}_{1}$ response (group $B$ ). $R_{5-9} / R_{20-24}$ ratios (SE) in groups $A_{1}, A_{2}$, and $B$ were $1.17(0.06), 1.06(0.05)$, and 1.03 $(0 \cdot 03)$. Only group $A_{1}$ had a baseline $R_{5-9} / R_{20-24}$ ratio that was significantly different from $1.0(\mathrm{p}<$ 0.05 ) - that is, $R_{T H}$ was frequency dependent in this group.

\section{Discussion}

The application of forced random noise oscillations to the airway has been used to characterise respiratory mechanical impedance. This technique has been shown to provide reliable impedance data in adults and in children. ${ }^{247}$ Effective resistance by this method (real part of impedance) reflects the combined resistances of the airways, lung tissue, and chest wall. For the airways, resistance at low frequencies is determined by the state of the peripheral and central airways, whereas resistance at high frequencies includes mostly the central airways component.' Forced random noise impedance data in normal subjects have shown that the effective resistance of the respiratory system is relatively independent of frequency between 5 and $30 \mathrm{~Hz}^{26}$ In some subjects with obstructive lung disease or in methacholine induced bronchoconstriction effective resistance at low frequencies is greater than in normal subjects and decreases in a curvilinear fashion with increasing frequency - that is, effective resistance is markedly frequency dependent. ${ }^{27}$

The ratio of effective resistance at low to high frequencies, $\mathbf{R}_{5-9} / \mathbf{R}_{15-19}$ or $\mathbf{R}_{5-9} / \mathbf{R}_{20-24}$ - has been used to obtain indirect information about the partitioning of resistance in the airways. This ratio has been reported to differ in young asymptomatic smokers compared with non-smokers. ${ }^{6}$ Subjects for our study group were selected for their bronchial sensitivity to cotton dust. This distinguishes them from similarly aged, asymptomatic subjects studied by others, ${ }^{67}$ and may account for their higher baseline effective resistance and the absence of a smoking effect on the $R_{5-9} / R_{20-24}$ ratio.

It is known that the inhalation of cotton dust can induce acute pulmonary function changes both in previously exposed people and in healthy subjects. ${ }^{12-14}$ Decrements in timed forced expiratory volumes and flows have repeatedly been shown and the partitioning of this increase in flow resistance has been examined by Bouhuys and co-workers. ${ }^{15} 16$. Reductions in maximum flow rates without a conductance response or change in static recoil pressures have suggested an important role for small airways narrowing in byssinosis.

In the current study small but statistically significant reductions in spirometric indices were observed for the study group as a whole after exposure to cotton dust. In addition, the measurement of respiratory impedance also detected exposure related changes in lung function. Observed changes in $\mathrm{FEF}_{75}, \mathbf{R}_{1}, \mathbf{R}_{5-9}$ and the $\mathbf{R}_{5-9} / \mathbf{R}_{20-24}$ ratio support the small airways effect described in previous studies of cotton induced bronchoconstriction.

Changes in large airways may also occur after exposure to certain vegetable dusts. Increases in airway resistance (Raw) have been observed both with and without a decline in $\mathrm{FEV}_{1}$ and maximum flow rates after inhalation of cotton or hemp dusts. ${ }^{1617}$ In our study group Raw measurements showed no significant difference between the dust and control exposures. This could not be ascribed to differences in demographic profiles or cotton induced spirometry and oscillator responses of subjects with and without Raw measurements. The lack of a statistically significant Raw response may reflect measurement variability in an experiment where both sample size and induced changes in lung function were small.

The impedance data suggest that in some subjects cotton dust caused an increase in effective resistance which was most pronounced in the central airways. For subjects with no $\mathrm{FEV}_{1}$ response to dust (table 3 ), statistically significant increases occurred in 
effective resistance at low and high frequencies $\left(R_{1}\right.$, $\left.R_{5-9}, R_{20-24}\right)$. This upward displacement of the resistance-frequency plot (fig 2, group B) is similar to that described when central resistance is increased by the application of an added external resistor. ${ }^{3}$ The discordance between Thevenin resistance and peak flow rate responses in $\mathrm{FEV}_{1}$ nonresponders (group B, table 3) may reflect the greater variability of the peak flow measurement. It may also be due to a systematic bias resulting from the use of FEV 1 to define response status. Since FEV and peak flow rate are both highly correlated and influenced by subject effort, subjects with a decline in peak flow or submaximal effort during postshift spirometry were more likely to be classified as FEV responders (group A, table 3 ).

Dust exposure in the present study occurred at a concentration $\left(0.46 \mathrm{mg} / \mathrm{M}^{3}\right)$ less than half that used to select participants. At the higher dose, all the study subjects showed decrements in forced expiratory volumes and flows which were qualitatively similar to those found in group $\mathrm{A}$ ( $\mathrm{FEV}_{1}$ responders) in the current experiment. We did not measure total respiratory impedance during the selection process, but we suspect that at a higher dose of cotton dust group $B$ subjects $\left(\mathrm{FEV}_{1}\right.$ non-responders) would show a frequency dependent $R_{T H}$ response similar to that observed in group $\mathrm{A}$ at the lower dose. Studies in hemp workers and in asthmatic patients suggest that this hypothesis is plausible. In a group of hemp workers ${ }^{16}$ and in some asthmatic patients studied by Stanescu and Brasseur, ${ }^{18}$ decrements in maximal expiratory flow rates without conductance responses were observed after hemp dust and histamine challenge. Among hemp workers with larger decrements in flow rate and after challenge with higher histamine doses in the asthmatic patients, both flow rates and conductance decreased. This suggests that with early or mild bronchoconstriction, some subjects may show a predominant effect on central airways (decreased conductance) and others a principal effect on peripheral airways (decreased flows at low lung volumes).

Baseline Thevenin resistance was observed to differ in our FEV 1 responders compared with nonresponders (fig 3). Subjects with the largest FEV decrements after dust exposure had higher preexposure $R_{T H}$ and frequency dependent baseline and dust induced increases in $R_{T H}$. An association between baseline lung function and site of airways response has also been observed in hemp workers ${ }^{16}$ and in some subjects with bronchial asthma. ${ }^{19} 20$

The data in table 2 provide important information regarding the magnitude of dust related changes and measurement variability for impedance and spirometric indices. In general, acute responses to cotton dust exposure are seen to be larger for Thevenin resistance than for maximal expiratory volumes and flows. Nevertheless, measurement variability for all spirometric indices except $\mathrm{FEF}_{75}$, assessed by comparing the standard errors of measurements for the no dust day (control exposure, table 2), is between $50 \%$ to $75 \%$ less than for impedance derived parameters. Thus whereas useful information regarding the partitioning of airway resistance may be obtained by this method, it may be more useful in the evaluation of acute responses in groups than in individuals.

Mention of product names does not constitute endorsement by the US Government or its agencies.

Requests for reprints to: M-J Sepulveda, MD, Clinical Investigations Branch, National Institute for Occupational Safety and Health, 944 Chestnut Ridge Road, Morgantown, WV 26505, USA.

\section{References}

${ }^{1}$ Dubois AB, Brody AW, Lewis DH, Burgess BF Jr. Oscillation mechanics of the lungs and chest in man. J Appl Physiol 1956;8: 587-94.

2 Michaelson ED, Grassman ED, Peters WR. Pulmonary mechanics by spectral analysis of forced random noise. J Clin Invest 1975; 56: 1210-29.

${ }^{3}$ Pimmel RL, Tsai MJ, Winter DC, Bromberg PA. Estimating central and peripheral resistance. $J$ Appl Physiol 1978;45:375-80.

4 Williams SP, Fullton JM, Tsai MJ, Pimmel RL, Collier AN. Respiratory impedance and derived parameters in young children by forced random noise. J Appl Physiol 1979;47:169-74.

s Slutsky AS, Drazen JM. Estimating central and peripheral respiratory resistance: an alternative analysis. J Appl Physiol 1979;47:1325-31.

- Hayes DA, Pimmel RL, Fullton JM, Bromberg PA. Detection of respiratory mechanical dysfunction by forced random noise impedance parameters. Am Rev Respir Dis 1979;120:1095100.

' Pimmel RL, Fullton JM, Ginsberg JF, et al. Correlation of airway. resistance with forced random noise resistance parameters. $J$ Appl Physiol 1981;51:33-9.

${ }^{8}$ Cocke JB, Castellan RM, Sasser PE, Hankinson JL. Pulmonary function response to washed and unwashed cotton. In: Wakelyn PJ, Jacobs RR, eds. Proceedings, seventh cotton dust research conference, beltwide cotton production research conferences. San Antonio, Texas: National Cotton Council \& the Cotton Foundation. 1983:62-6.

- American Thoracic Society. Standardization of spirometry. Am Rev Respir Dis 1979;119:831-8.

${ }^{10}$ Knudson RJ, Slatin RC, Lebowitz MD, Burrows B. The maximal expiratory flow-volume curve: normal standards, variability, and effects of age. Am Rev Respir Dis 1976;113:587-600.

" Fukunaga K. Introduction to statistical pattern recognition. London: Academic Press Inc, 1972:90-121.

${ }^{12}$ McKerrow CB, Molyneux MKB. The influence of previous dust exposure on the acute respiratory effects of cotton dust inhalation. 2nd International conference on respiratory diseases in textile workers, Alicante, Spain. 1968. Permanent Commission and International Association on Occupational Health.

${ }^{13}$ Berry G, McKerrow CB, Molyneux MKB, Rossiter CE, Tomble- 
son JBL. A study of acute and chronic changes in ventilatory capacity of workers in the Lancashire cotton mills. $\mathrm{Br} J$ Ind Med 1973;30:25-36.

14 Merchant JA, Halprin GM, Hudson AR, et al. Responses to cotton dust. Arch Environ Health 1975;30:222-9.

is Bouhuys A, Nichols PJ. The effect of cotton dust on respiratory mechanics in man and in guinea pigs. In: Davies $\mathrm{CN}$, ed. Inhaled particles and vapours II. Oxford: Pergamon Press Ltd, 1967:75-83.

${ }^{16}$ Bouhuys A, van de Woestijne KP. Respiratory mechanics and dust exposure in byssinosis. $J$ Clin Invest 1970;49:106-18.

${ }^{17}$ McDermott M, Nichols J, Edwards J, Skidmore J. The physiological, immunological and pharmacological effects of inhaled cotton dusts. 2nd International conference of respiratory dis- eases in textile workers, Alicante, Spain, 1968. Permanent Commission and International Association on Occupational Health.

18 Stanescu DC, Brasseur LA. Maximal expiratory flow rates and airway resistance following histamine aerosols in asthmatics. Scand J Respir Dis 1973;54:333-40.

${ }^{19}$ Chan-Yeung MMW, Abboud R, Tsao MS, Maclean L. Effect of helium on maximal expiratory flow in patients with asthma before and during induced bronchonconstriction. Am Rev Respir Dis 1976;113:433-43.

${ }^{20}$ McFadden ER, Ingram RH, Haynes RL, Wellman JJ. Predominant site of airflow limitation and mechanisms of postexertional asthma. J Appl Physiol 1977;42:746-52.

\section{Vancouver style}

All manuscripts submitted to the $B r J$ Ind Med should conform to the uniform requirements for manuscripts submitted to biomedical journals (known as the Vancouver style).

The $\mathrm{Br} J$ Ind Med, together with many other international biomedical journals, has agreed to accept articles prepared in accordance with the Vancouver style. The style (described in full in $\mathrm{Br}$ Med J, 24 February 1979, p 532) is intended to standardise requirements for authors.

References should be numbered consecutively in the order in which they are first mentioned in the text by Arabic numerals above the line on each occasion the reference is cited (Manson' confirmed other reports ${ }^{2-5} \ldots$.). In future references to papers submitted to the $B r J$ Ind Med should include: the names of all authors if there are six or less or, if there are more, the first three followed by $e t$ al; the title of journal articles or book chapters; the titles of journals abbreviated according to the style of Index Medicus; and the first and final page numbers of the article or chapter.

Examples of common forms of references are:

' International Steering Committee of Medical Editors. Uniform requirements for manuscripts submitted to biomedical journals. Br Med J 1979; 1:532-5.

${ }^{2}$ Soter NA, Wasserman SI, Austen KF. Cold urticaria: release into the circulation of histamine and eosinophil chemotactic factor of anaphylaxis during cold challenge. $N$ Engl $J$ Med 1976;294:687-90.

${ }^{3}$ Weinstein L, Swartz MN. Pathogenic properties of invading micro-organisms. In: Sodeman WA Jr, Sodeman WA, eds. Pathologic physiology: mechanisms of disease. Philadelphia: W B Saunders, 1974:457-72. 